Shailesh Bihari

Michael Bailey

Andrew D. Bersten

\title{
Steroids in ARDS: to be or not to be
}

Received: 28 October 2015

Accepted: 30 October 2015

Published online: 16 November 2015

(C) Springer-Verlag Berlin Heidelberg and ESICM 2015

S. Bihari · A. D. Bersten ( $\bullet)$

Department of Critical Care Medicine, Flinders University,

Bedford Park, SA, Australia

e-mail: andrew.bersten@ flinders.edu.au

Tel.: +61-8-82044247

S. Bihari - A. D. Bersten

Department of Intensive Care Medicine, Flinders Medical Centre, Bedford Park, SA, Australia

M. Bailey

Department of Epidemiology and Preventive Medicine, Australian and New Zealand Intensive Care Research Centre, Monash University, Melbourne, Australia

Glucocorticoid treatment of acute respiratory distress syndrome (ARDS) remains contentious, and the available evidence remains contradictory [1-4]. In this context, the current analysis by Meduri et al. [5] is welcome. These authors conducted a two-part analysis-(1) individual patient data meta-analysis (IPDMA) from trials with methylprednisolone and (2) an updated trial-level metaanalysis including additional randomised controlled trials (RCTs) with hydrocortisone in early ARDS - and have reported that steroids accelerated the resolution of ARDS, leading to reduced ventilatory assistance, hospital mortality and health care utilisation [5]. However, these conclusions appear to contradict those of the ARDS Network LaSRS study [4], which contributed $56 \%$ of the patients to the IPDMA. Furthermore, in addition to reporting no benefit from the routine use of methylprednisolone in patients with ARDS, the LaSRS investigators found that the use of methylprednisolone was associated with an increased risk of neuromuscular complications and that initiation of methylprednisolone treatment more than 2 weeks after the onset of ARDS led to an increase in the risk of death despite improved early cardiopulmonary physiology [4]. This discrepancy demands some consideration.

Meta-analysis offers some advantages over a single high-quality RCT, as the greater number of patients enrolled in the former, as well as the range of differing populations, circumstances and settings, facilitates generalisability. However, studies in critical care settings are particularly challenging due to the heterogeneity of both the cohort and the treatments, which can lead to misleading conclusions [6]. While this is minimised in IPDMA [7], which is considered the gold standard for meta-analysis [8], and therefore is the focus of our attention here, both the quality of the individual studies included in the IPDMA and of the analysis itself need to be considered.

Well-documented and published guidelines (PRISMA) for the conduct, reporting and transparency of metaanalysis [9]—and specifically for IPDMA [10] —have been developed. Despite Meduri et al.'s detailed description of the statistical methods used in their IPDMA [5], the information provided is insufficient to conclude that these guidelines were all followed. In addition, there was moderate heterogeneity in study outcomes (reported as an $I^{2}$ statistic, with likely wide $95 \%$ confidence intervals), which the authors attribute to the LaSRS study. These methodological concerns suggest that the reader should be cautious in drawing conclusions.

There are important differences in trial design between the studies contributing data to the IPDMA of Meduri et al. [5]. The LaSRS study enrolled 180 patients (1:1 randomisation), with 60-day mortality as its primary 
Table 1 Details of primary outcome, total number, tidal volume and plateau pressure for studies included in the individual patient data meta-analysis

\begin{tabular}{|c|c|c|c|c|c|c|c|}
\hline \multirow[t]{2}{*}{ Study } & \multirow[t]{2}{*}{ Primary outcome } & \multirow{2}{*}{$\begin{array}{l}\text { Study } \\
\text { arm }\end{array}$} & \multirow{2}{*}{$\begin{array}{l}\text { Number of } \\
\text { participants in } \\
\text { each study arm }\end{array}$} & \multicolumn{2}{|c|}{ Tidal volume } & \multicolumn{2}{|c|}{ Plateau pressure $^{\mathrm{a}}$} \\
\hline & & & & $n^{\mathrm{a}}$ & $\begin{array}{l}\text { Mean } \pm \text { SD } \\
(\mathrm{ml} / \mathrm{kg} / \mathrm{pbw})^{\mathrm{b}}\end{array}$ & $n^{\mathrm{a}}$ & $\begin{array}{l}\text { Mean } \pm \text { SD } \\
\left(\mathrm{cm} \mathrm{H} \mathrm{H}_{2} \mathrm{O}\right)^{\mathrm{b}}\end{array}$ \\
\hline \multirow[t]{2}{*}{ Meduri et al. [1] } & \multirow[t]{2}{*}{ Improvement in LIS by day 14} & Placebo & 8 & 7 & $10.1 \pm 3.0$ & 5 & $43.0 \pm 2.2$ \\
\hline & & MP & 16 & 14 & $10.9 \pm 2.3$ & 11 & $37.8 \pm 6.3$ \\
\hline \multirow[t]{2}{*}{ Steinberg et al. [4] } & \multirow[t]{2}{*}{ 60-day mortality } & Placebo & 91 & 77 & $7.2 \pm 2.3$ & 65 & $33.8 \pm 9.7$ \\
\hline & & MP & 89 & 77 & $7.1 \pm 2.2$ & 66 & $34.5 \pm 10.0$ \\
\hline \multirow[t]{2}{*}{ Meduri et al. [3] } & \multirow[t]{2}{*}{ Improvement in LIS by day 7} & Placebo & 28 & 25 & $11.3 \pm 2.8$ & 13 & $29.0 \pm 4.5$ \\
\hline & & MP & 63 & 57 & $10.5 \pm 2.8$ & 30 & $29.9 \pm 8.2$ \\
\hline \multirow[t]{2}{*}{ Rezk and Ibrahim [2] } & \multirow[t]{2}{*}{ Improvement in LIS by day 14} & Placebo & 9 & - & - & - & - \\
\hline & & MP & 18 & - & - & - & - \\
\hline
\end{tabular}

LIS Lung injury score, MP methylprednisolone, SD standard deviation

${ }^{\text {a }} n$ is the number of patients for which tidal volume and plateau pressure data were available

b Data for tidal volume and plateau pressure for Meduri et al. [1] and Meduri et al. [3] were retrospectively collected from respiratory flow sheets. No tidal volume and plateau pressure data were available from the study of Rezk and Ibrahim [2]

outcome [4]; the remaining studies used a 2:1 randomisation ( $n=24$ [1], 27 [2] and 91 [3]), with reduction in the lung injury score at day 7 [3] or day $14[1,2]$ as the primary outcome (Table 1) and only mortality at day 28 reported. Despite early improvements in cardiopulmonary physiology and an increased number of ventilator-free days, intensive care unit-free days and shock-free days during the first 28 days of treatment, patients treated with methylprednisolone in the LaSRS study did not show improved outcomes at day 60 and day 180 and had greater neuromuscular weakness and an increase in mortality if the treatment had been started after 14 days. While Meduri et al. [5] cogently argue that the rapid cessation of methylprednisolone resulted in an exacerbation of lung inflammation, contributing to these adverse effects, these data also emphasise the importance of examining longerterm outcomes [11]. Mortality is both unambiguous and unarguably important, but it does depend upon when it is measured [12], and current data are limited to treatment day 28 or hospital mortality. Long-term functional disability is an equally important legacy in ARDS survivors [13] and is an increasing focus for both researchers and clinicians.

There are also differences in routine care (co-interventions) in the studies included in the IPDMA that may contribute to heterogeneous outcomes. Lung protective mechanical ventilation has generally become the standard of care for ARDS patients. It is of note that barring the LaSRS study [4], the other three studies [1-3] used tidal volumes that would not be considered lung protective (Table 1). Other factors, such as use of neuromuscular blocking agents [14] and fluid balance, can also affect the outcome of patients with ARDS.
Taken together, these factors raise the question of standardisation, where possible, and the potential bias of co-interventions during a clinical trial. For example, while magnesium was found to improve outcome from myocardial infarction in LIMIT-2 $(n=2316)$ [15], this was not confirmed in the ISIS-4 mega-trial $(n=58,050)$ [16]. An important difference between these latter two studies was the much greater use of aspirin and attempted revascularisation in ISIS-4 [16]. It is unknown whether protective ventilation mitigates the beneficial effects of steroids in ARDS, but clinicians should consider the possible bias introduced by unbalanced cointerventions when interpreting data from both RCTs and meta-analyses.

The potential adverse effects of therapeutic steroids go beyond neuromuscular weakness, immunosuppression, superadded infection and higher blood glucose levels [17]. The mineralocorticoid effect of steroids contributes to fluid and sodium retention $[18,19]$, with both a positive fluid and sodium balance associated with adverse outcomes in patients with lung injury [20-22]. Prospective data examining this potential confounder should be considered in future clinical trials.

On the principle of primum non nocere (first, do no harm), we feel that there is currently insufficient evidence to advocate the routine use of steroids in patients with ARDS as potential short-term improvements appear to be mitigated by later adverse effects. If steroids are used, however, abrupt cessation should be avoided.

\section{Compliance with ethical standards}

Conflicts of interest None. 


\section{References}

1. Meduri GU, Headley S, Golden E, Carson S, Umberger R, Kelso T, Tolley E (1998) Effect of prolonged methylprednisolone therapy in unresolving acute respiratory distress syndrome. A randomized controlled trial. JAMA 280:159-165

2. Rezk N, Ibrahim A (2013) Effects of methylprednisolone in early ARDS. Egypt J Chest Dis Tuberc 62:167-172

3. Meduri GU, Golden E, Freire AX, Taylor E, Zaman M, Carson SJ, Gibson M, Umbergere R (2007) Methylprednisolone infusion in early severe ARDS: results of a randomized controlled trial. Chest 131:954-963

4. Steinberg KP, Hudson LD, Goodman RB, Hough CL, Lanken PN, Hyzy R, Thompson BT, Ancukiewicz M (2006) Efficacy and safety of corticosteroids for persistent acute respiratory distress syndrome. N Engl J Med 354:1671-1684

5. Meduri GU, Bridges L, Shih MC, Siemieniuk RA, Marik PE, Kocak M (2015) Prolonged glucocorticoid treatment is associated with improved ARDS outcomes: analysis of individual patients' data from four randomized trials and trial-level metaanalysis of the updated literature. Intensive Care Med. doi:10.1007/s00134-015-4095-4

6. Reade MC, Delaney A, Bailey MJ, Angus DC (2008) Bench-to-bedside review: avoiding pitfalls in critical care meta-analysis-funnel plots, risk estimates, types of heterogeneity, baseline risk and the ecologic fallacy. Crit Care 12:220

7. Stewart LA, Clarke MJ (1995) Practical methodology of meta-analyses (overviews) using updated individual patient data Cochrane Working Group. Stat Med 14:2057-2079
8. Chalmers I (1993) The Cochrane collaboration: preparing, maintaining, and disseminating systematic reviews of the effects of health care. Ann N Y Acad Sci 703:156-163

9. Moher D, Liberati A, Tetzlaff J, Altman DG, Group P (2009) Preferred reporting items for systematic reviews and metaanalyses: the PRISMA statement. BMJ 339:b2535

10. Stewart LA, Clarke M, Rovers M, Riley RD, Simmonds M, Stewart G et al (2015) Preferred reporting Items for systematic review and meta-analyses of individual participant data: the PRISMA-IPD Statement. JAMA 313:1657-1665

11. Needham DM (2014) Understanding and improving clinical trial outcome measures in acute respiratory failure. Am J Respir Crit Care Med 189:875-877

12. Moss M (2015) Mortality is the only relevant outcome in ARDS: yes. Intensive Care Med 41:141-143

13. Herridge MS, Tansey CM, Matté A, Tomlinson G, Diaz-Granados N, Cooper A, Guest CB, Mazer CD, Mehta S, Stewart TE, Kudlow P, Cook D, Slutsky AS, Cheung AM, Canadian Critical Care Trials Group (2011) Functional disability 5 years after acute respiratory distress syndrome. N Engl J Med 364:1293-1304

14. Papazian L, Forel JM, Gacouin A, Penot-Ragon C, Perrin G, Loundou A, Jaber S, Arnal JM, Perez D, Seghboyan JM, Constantin JM, Courant P, Lefrant JY, Guérin C, Prat G, Morange S, Roch A, ACURASYS Study Investigators (2010) Neuromuscular blockers in early acute respiratory distress syndrome. N Engl J Med 363:1107-1116

15. Woods KL, Fletcher S (1994) Longterm outcome after intravenous magnesium sulphate in suspected acute myocardial infarction: the second Leicester intravenous magnesium intervention trial (LIMIT-2). Lancet 343:816-819
16. ISIS-4 (1995) a randomised factorial trial assessing early oral captopril, oral mononitrate, and intravenous magnesium sulphate in 58,050 patients with suspected acute myocardial infarction. ISIS-4 (Fourth International Study of Infarct Survival) Collaborative Group. Lancet 345:669-685

17. Cronin L, Cook DJ, Carlet J et al (1995) Corticosteroid treatment for sepsis: a critical appraisal and meta-analysis of the literature. Crit Care Med 23:1430-1439

18. Lieberman P, Patterson R, Kunske R (1972) Complications of long-term steroid therapy for asthma. J Allergy Clin Immunol 49:329-336

19. Zuckerman S, Palmer A, Da Hanson (1950) The effect of steroid hormones on the water content of tissues. J Endocrinol 6:261-276

20. National Heart, Lung, and Blood Institute Acute Respiratory Distress Syndrome (ARDS) Clinical Trials Network, Wiedemann HP, Wheeler AP, Bernard GR et al (2006) Comparison of two fluid-management strategies in acute lung injury. N Engl J Med 354:2564-2575

21. Bihari S, Peake SL, Prakash S, Saxena M, Campbell V, Bersten A (2015) Sodium balance, not fluid balance, is associated with respiratory dysfunction in mechanically ventilated patients: a prospective, multicentre study. Crit Care Resusc 17:23-28

22. Neamu RF, Martin GS (2013) Fluid management in acute respiratory distress syndrome. Curr Opin Crit Care 19:24-30 